\title{
Tuning Electronic and Ionic Conductivities in
}

\section{Composite Materials for Electrochemical}

\section{Devices}

Nerea Casado, , ' Sara Zendegi, † Rafael del Olmo, ' Antonio Dominguez-Alfaro,

$t, \mathcal{S}$ Maria Forsyth ${ }^{*}, t, \downarrow$

†POLYMAT, University of the Basque Country UPV/EHU, Joxe Mari Korta

Center, Ave. Tolosa 72, 20018 Donostia-San Sebastián, Spain.

${ }^{\ddagger} A R C$ Centre of Excellence for Electromaterials Science (ACES), Deakin

University, Burwood, VIC 3125, Australia

Ikerbasque, Basque Foundation for Science, E-48011 Bilbao, Spain

\$Present address: CIC biomaGUNE, Carbon BioNanotechnology group, Miramon

Pasealekua, 182, San Sebastian 20014, Spain 
E-mail: Nerea.casado@ehu.eus,maria.forsyth@deakin.edu.au 
Table S1. Phase transition onset temperatures and entropies of pure $\left[\mathrm{C}_{2} \mathrm{mpyr}\right][\mathrm{FSI}]$ and composites with PEDOT-Cl.

\begin{tabular}{|c|c|c|c|c|c|c|}
\hline & III-II $\left[{ }^{\circ} \mathrm{C}\right]$ & $\begin{array}{c}\Delta \mathrm{S} \\
{\left[\mathrm{J} \mathrm{g}^{-1}\right]}\end{array}$ & II-I $\left[{ }^{\circ} \mathrm{C}\right]$ & $\begin{array}{c}\Delta \mathrm{S} \\
{\left[\mathrm{J} \mathrm{g}^{-1}\right]}\end{array}$ & Melt $\left[{ }^{\circ} \mathrm{C}\right]$ & $\Delta \mathrm{S}\left[\mathrm{J} \mathrm{g}^{-1}\right]$ \\
\hline$\left[\mathrm{C}_{2} \mathrm{mpyr}\right][\mathrm{FSI}]$ & -67 & 33 & -22 & 4 & 202 (peak) & 21 \\
\hline 10/90 PEDOT-Cl / [C $\left.\mathrm{C}_{2} \mathrm{mpyr}\right][\mathrm{FSI}]$ & -71 & 12 & -23 & 3 & 184 (peak) & 3 \\
\hline 20/80 PEDOT-Cl / [C $\left.\mathrm{C}_{2} \mathrm{mpyr}\right][\mathrm{FSI}]$ & -70 & 9 & -19 & 2 & 174 (peak) & 3 \\
\hline 30/70 PEDOT-Cl / [C $\left.\mathrm{C}_{2} \mathrm{mpyr}\right][\mathrm{FSI}]$ & -67 & 8 & -19 & 1 & 110 (peak) & 2 \\
\hline 40/60 PEDOT-Cl / [C $\left.\mathrm{C}_{2} \mathrm{mpyr}\right][\mathrm{FSI}]$ & -65 & 7 & -14 & $<1$ & 61 (peak) & $<1$ \\
\hline 50/50 PEDOT-Cl / [C $\left.\mathrm{C}_{2} \mathrm{mpyr}\right][\mathrm{FSI}]$ & - & - & - & & - & \\
\hline
\end{tabular}

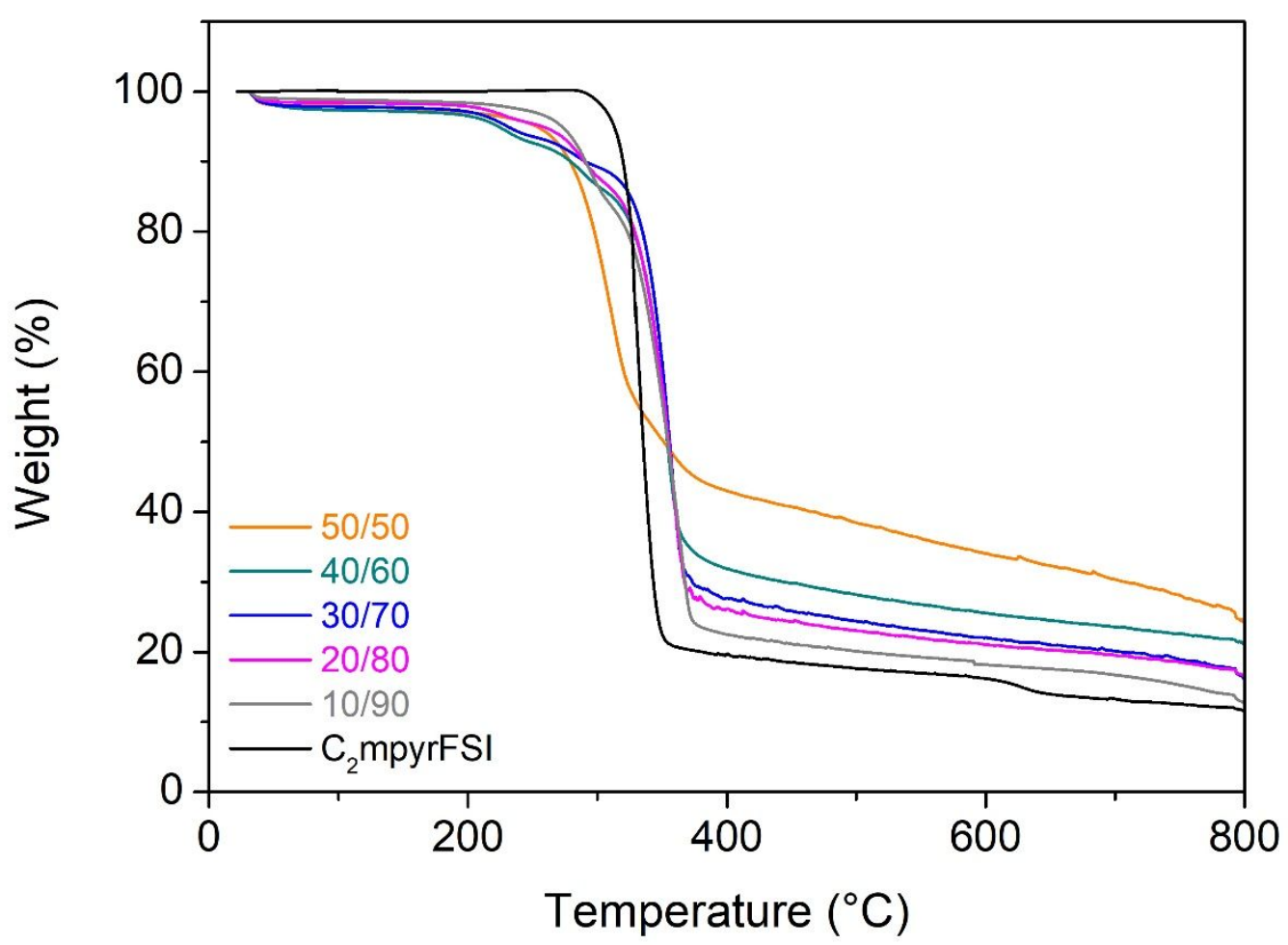

Figure S1. Thermogravimetric analysis of neat $\left[\mathrm{C}_{2} \mathrm{mpyr}\right][\mathrm{FSI}]$ (black) and different PEDOT-Cl/[C $\left.\mathrm{C}_{2} \mathrm{mpyr}\right][\mathrm{FSI}]$ composites as shown in the figure legends. 


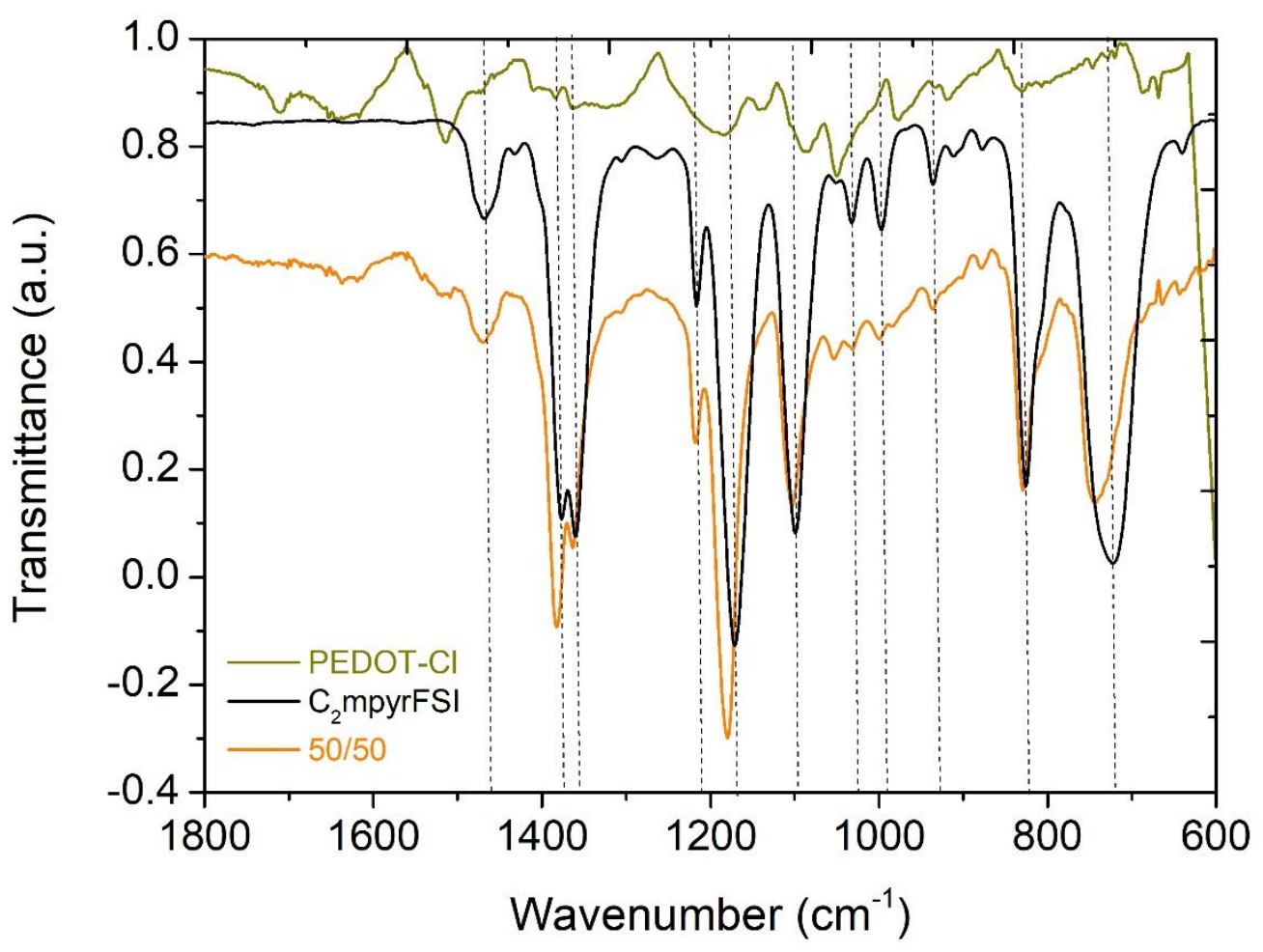

Figure S2. FT-IR spectra of neat PEDOT-Cl, [C $\left.\mathrm{C}_{2} \mathrm{mpyr}\right][\mathrm{FSI}]$ and 50/50 PEDOT$\mathrm{Cl} /\left[\mathrm{C}_{2} \mathrm{mpyr}\right][\mathrm{FSI}]$ composite. 

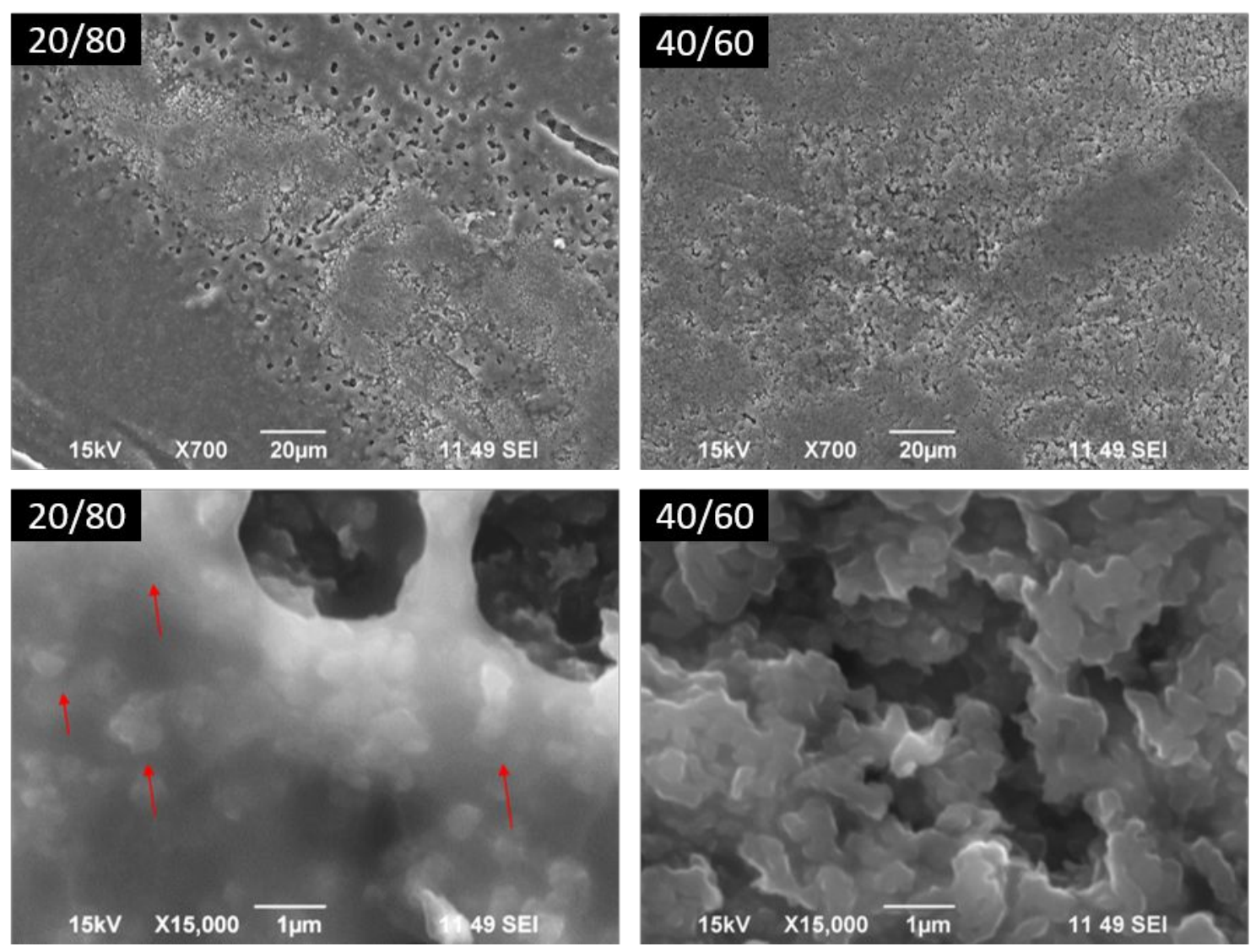

Figure S3. SEM images of 20/80 and 40/60 PEDOT-Cl/[C $\left.\mathrm{C}_{2} \mathrm{mpyr}\right][\mathrm{FSI}]$ composites at low (top images) and high magnification (down images). The red arrows point at PEDOT-Cl particle aggregates in the OIPC matrix. 
(a)

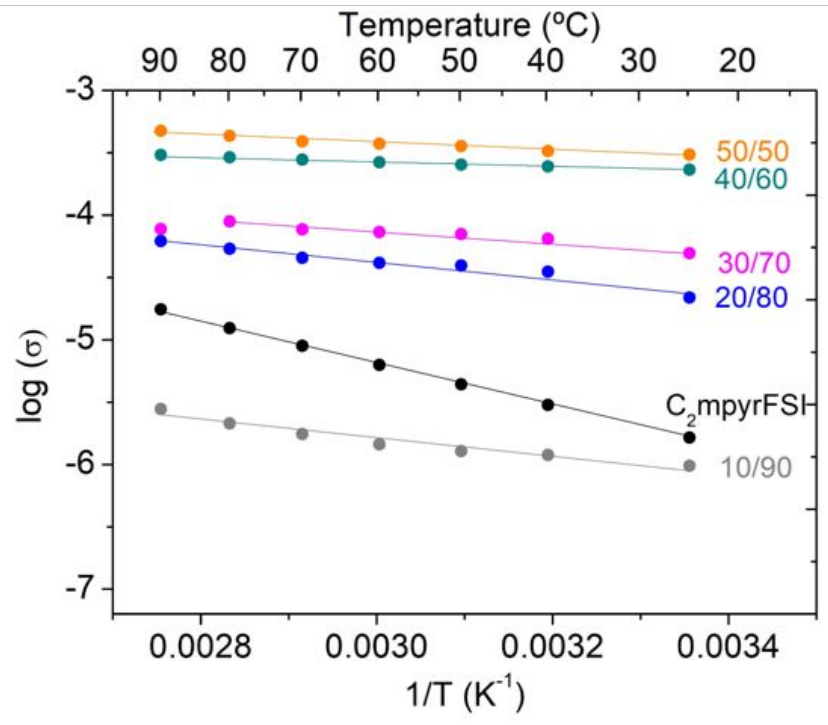

(b)

\begin{tabular}{lc}
\hline & Ea \\
& {$\left[\mathrm{KJ} \mathrm{mol}^{-1}\right]$} \\
\hline$\left[\mathrm{C}_{2} \mathrm{mpyr}\right][\mathrm{FSI}]$ & $14.18 \pm 0.15$ \\
$10 / 90$ & $6.01 \pm 0.67$ \\
$20 / 80$ & $5.61 \pm 0.61$ \\
$30 / 70$ & $3.64 \pm 0.44$ \\
$40 / 60$ & $1.65 \pm 0.07$ \\
$50 / 50$ & $2.59 \pm 0.21$ \\
\hline
\end{tabular}

Figure S4. (a) Arrhenius plot and (b) activation energies (Ea) extracted from the linear regression of the Arrhenius plots for pure $\left[\mathrm{C}_{2} \mathrm{mpyr}\right][\mathrm{FSI}]$ and composites with PEDOT$\mathrm{Cl}$. 


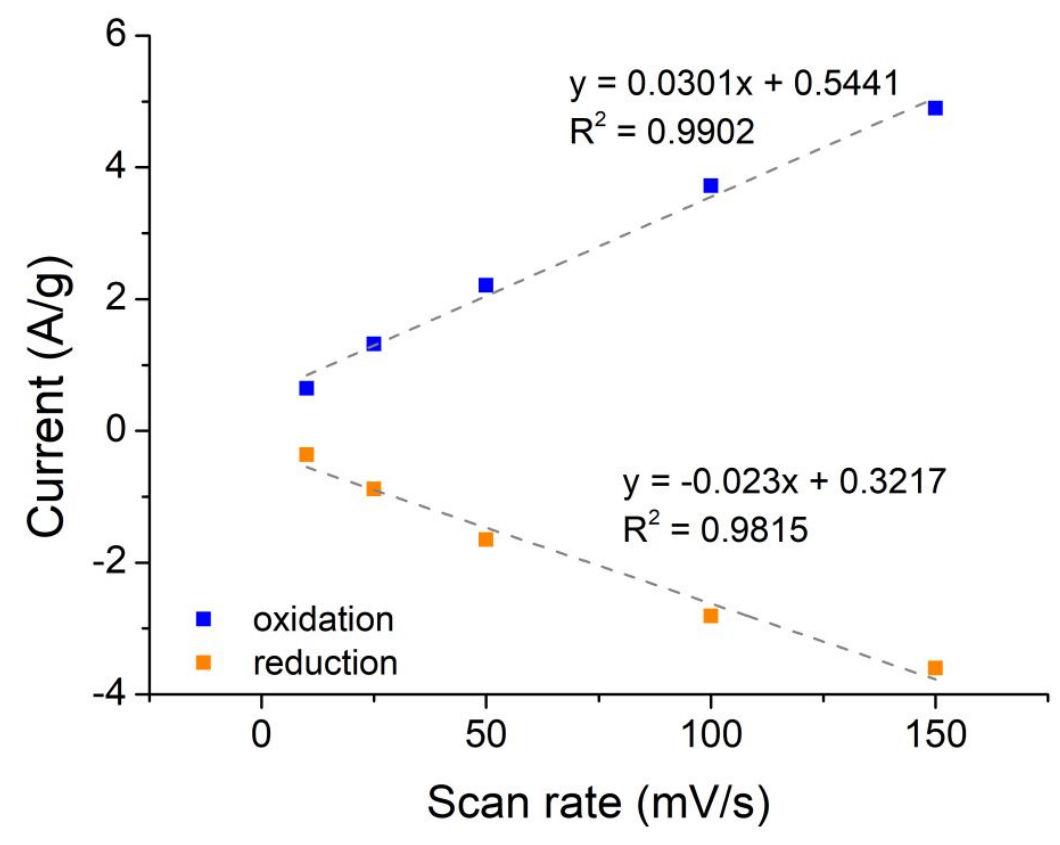

Figure S5. Anodic and cathodic peak current dependence over the scan rate of 40/60 PEDOT-Cl/[C $\left.\mathrm{C}_{2} \mathrm{mpyr}\right][\mathrm{FSI}]$ composite. 
(a)

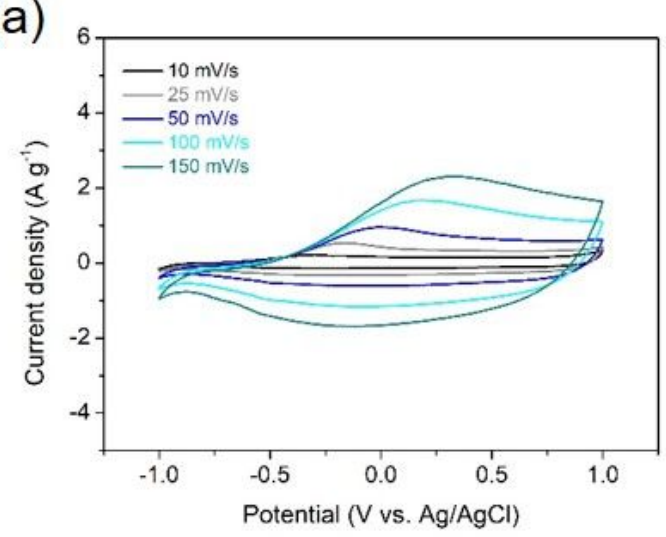

(c)

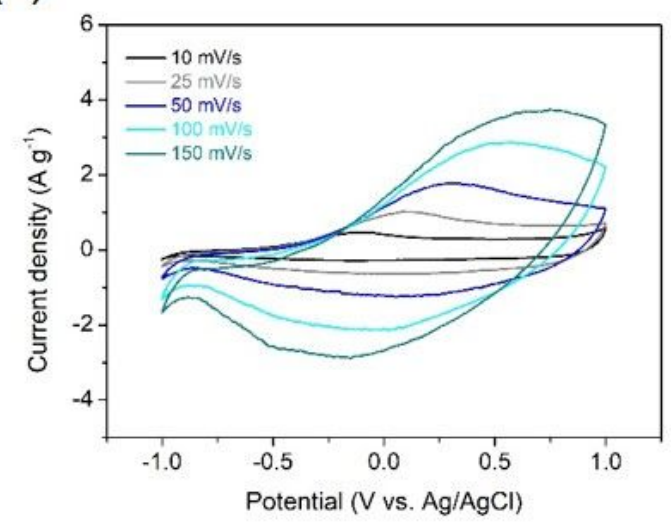

(b)

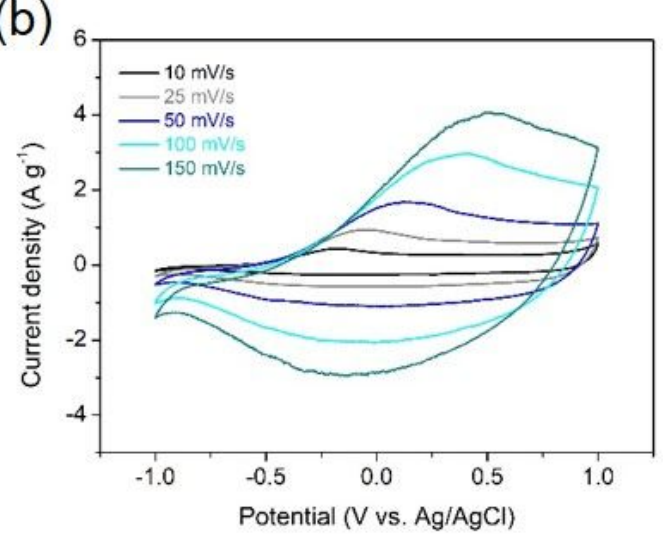

(d)

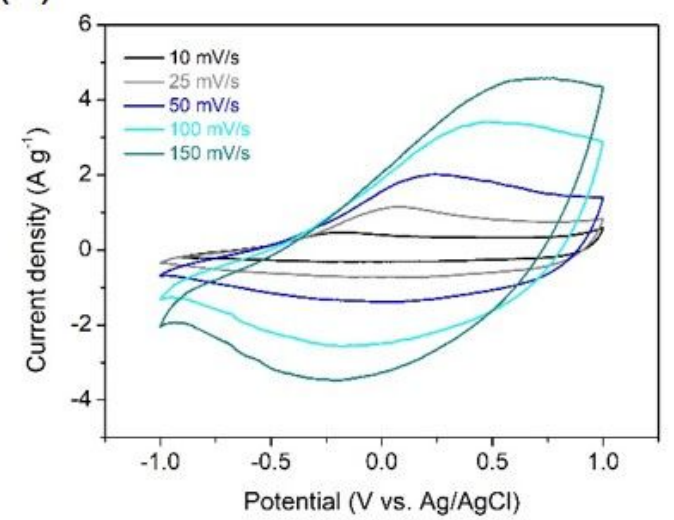

(e)

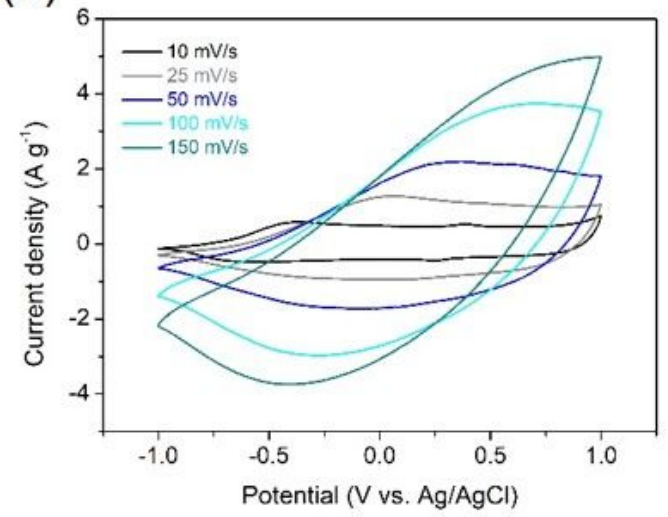

Figure S6. Cyclic voltammetries in 0.1 M KFSI aqueous electrolyte of PEDOT-

$\mathrm{Cl} / \mathrm{C}_{2}$ mpyrFSI composites: (a) 10/90, (b) 20/80, (c) 30/70, (d) 50/50 and (e) neat PEDOT-Cl. 


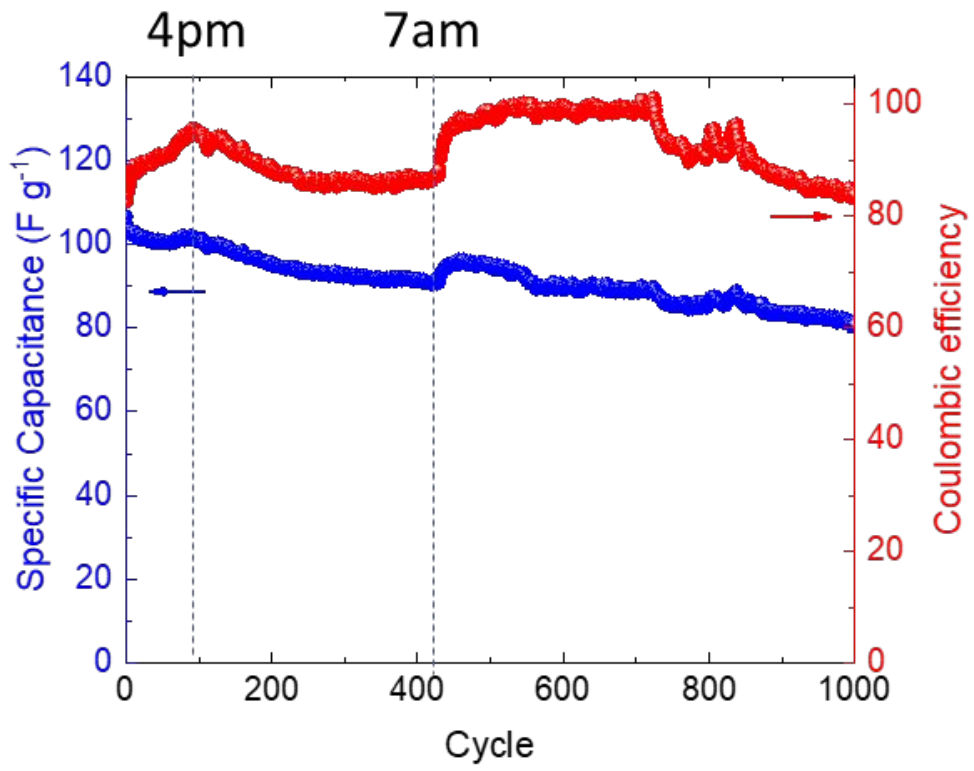

Figure S7. Specific capacitance and coulombic efficiency of the low loading 40/60 PEDOT-Cl/[C $\left.\mathrm{C}_{2} \mathrm{mpyr}\right][\mathrm{FSI}]$ electrode $\left(4.8 \mathrm{mg} \mathrm{cm}^{-2}\right)$ at $1 \mathrm{~A} \mathrm{~g}^{-1}$. The up and downs in the specific capacity are probably due to temperature oscillation during the experiment. 